\title{
A Ética individual e sua importância para a vida em sociedade
}

\author{
Individual Ethics and its importance for life in Society
}

Recebido: 25/01/2022 | Revisado: 29/01/2022 | Aceito: 04/02/2022 | Publicado: 05/02/2022

Pacifico Ferraz Souto

ORCID: https://orcid.org/0000-0001-9639-665X Universidad Columbia del Paraguay, Paraguai

E-mail: Pacifico.souto@educacao.mg.gov.br

Aline Dos Santos Moreira de Carvalho

ORCID: https://orcid.org/0000-0001-9965-9566 Universidad Columbia del Paraguay, Paraguai E-mail: bioaline2017@yahoo.com

Léia Flauzina da Silva Albuquerque

ORCID: https://orcid.org/0000-0002-6942-1116 Universidad Columbia del Paraguay, Paraguai

E-mail: psicopedagogarjleiaflauzina @ gmail.com

Gabrielle Oliveira dos Santos Anchieta

ORCID: https://orcid.org/0000-0003-1160-569X Universidad Columbia del Paraguay, Paraguai E-mail: gabbiosantos@yahoo.com

Lana Cristina de Almeida Silva

ORCID: https://orcid.org/0000-0003-1391-5034 Universidad Columbia del Paraguay, Paraguai E-mail: lanamestranda@gmail.com

Péricles Queiroz Araujo

ORCID: https://orcid.org/0000-0003-4155-159X Universidad Columbia del Paraguay, Paraguai E-mail: apericles72@gmail.com

Ingrid dos Santos Pereira

ORCID: https://orcid.org/0000-0002-9321-8564 Universidad Columbia del Paraguay, Paraguai E-mail: isp.pedagoga@gmail.com

Erika dos Santos Pereira

ORCID: https://orcid.org/0000-0002-2995-2385 Universidad Columbia del Paraguay, Paraguai E-mail: espereira1337@gmail.com

Veronica Cristina Pinto de Amorim

ORCID: https://orcid.org/0000-0001-6989-4362

Universidad Columbia del Paraguay, Paraguai

E-mail: Veronicaamorim382@gmail.com

\begin{abstract}
Resumo
A Ética é a ciência que objetiva estudar os juízos de aprovação ou não das condutas e vontades humanas, determinando critérios, dos quais como vontade e conduta operam, se distinguem, se relacionam, qual a finalidade, suas relações de valor. Considerando a ética individual a forma como os sujeitos se posicionam eticamente diante da sociedade, o presente estudo objetiva, brevemente, conceituar ética, ética individual e delimitar sua importância na sociedade. Para tal, utilizou-se de pesquisa bibliográfica. Os resultados e discussões foram dispostos em dois tópicos, dos quais: Ética, conceito e Ética individual e sua importância, e as conclusões nas considerações finais.
\end{abstract}

Palavras-chave: Ética; Ética individual; Sociedade.

\begin{abstract}
Ethics is the science that aims to study the judgments of approval or not of human conduct and will, determining criteria, from which how will and conduct operate, are distinguished, related, what is the purpose, their value relationships. Considering individual ethics as the way subjects ethically position themselves before society, the present study aims, briefly, to conceptualize ethics, individual ethics and to delimit their importance in society. To this end, a bibliographic research was used. The results and discussions were arranged in two topics, of which: Ethics, concept and individual Ethics and its importance, and the conclusions in the final considerations.
\end{abstract}

Keywords: Ethics; Individual ethics; Society. 


\section{Introdução}

A Ética é a ciência que tem como objeto de estudo os juízos de aprovação ou não das condutas e vontade humanas, dispondo-se a determinar alguns critérios como vontade e conduta operam, se distinguem, se relacionam, qual a finalidade, suas relações de valor, dentre outros aspectos.

Nesse contexto, considera-se a ética individual, a forma pela qual os sujeitos se posicionam eticamente ou não diante de problemáticas e da sociedade.

Nessa perspectiva, o presente estudo objetiva, brevemente, conceituar ética, ética individual e delimitar sua importância na sociedade. Para tal, utilizou-se de pesquisa bibliográfica, conforme concepção de Gil (2008).

\section{2. Ética, Conceito}

Figueiredo (2008) afirma que as discussões a respeito de ética necessitam abarcar as origens do termo e seus significados para que sejam, de fato, compreendidas uma vez que das origens surgem as ambiguidades de conceitos e significados. A palavra ethos expressa o existir do mundo grego que permanece na cultura atual. A palavra grega possui duas grafias que geram significados distintos e diversos que, ao longo do tempo, perderam o conceito original distanciando-se da raiz significativa. Porém, os principais significados da primeira grafia (êthos) são: "morada ou abrigo" - no sentido de proteção; "modo de ser ou caráter", de significância aristotélica, mais usado na tradição filosófica do ocidente. Nesse contexto, o ético compreende as disposições do homem na vida e sociedade, seu caráter, seus costumes e sua moral, ou forma de visa; e para simplificar o entendimento, define-se ética como palavra derivada do grego que significa modo de ser ou caráter.

A segunda grafia (éthos) significa hábitos e costumes, sendo esse de caráter social (hábitos, costumes, tradição). Compreendem atos concretos e reais através dos quais os indivíduos realizam seus projetos de vida, formando seu caráter moral mediante as decisões individuais na vida e, pela força das tradições, as sociedades são formadas. Nessa perspectiva ethos é o caráter impresso no indivíduo, através dos hábitos, que geram as tradições pelas quais as sociedades são formadas (Figueiredo, 2008).

A concepção clássica e a moderna conceituam ética como disciplina ou ciência que se ocupa dos atos morais e dos hábitos na significância de virtudes e vícios (Aranguren, 1972 apud Figueiredo, 2008).

A ética estuda as relações entre o indivíduo e o contexto em que está situado. Ou seja, entre o que é individualizado e o mundo a sua volta [mundo moral]. Procura enunciar e explicar as regras [sobre as quais se fundamenta a ação humana ou razão pela qual se deve fazer algo], normas, leis e princípios que regem os fenômenos éticos. São fenômenos éticos todos os acontecimentos que ocorrem nas relações entre o indivíduo e o seu contexto (Korte, 1999, p. 64 -115 apud Figueiredo, 2008, p. 4)

Cubelles (2002 apud Figueiredo) afirma que ética filosófica é uma metalinguagem que compreende a práxis humana, buscando as razões dos atos e considerando os valores morais de determinada sociedade.

Enquanto disciplina teórica, a ética estuda os códigos de valores determinantes para comportamento e influenciadores em tomadas de decisões em contextos específicos. Tais códigos compreendem um conjunto consensual de princípios morais, determinantes para atitudes ou não de acordo com o que é considerado bom ou ruim, por determinadas sociedades (Almeida, 2007).

\section{3. Ética Individual e sua Importância}

O comportamento ético acontece em três níveis que são, o individual, organizacional e cultural. A nível individual muitos são os estudos realizados a fim de explicar a postura ética a partir de algumas características individuais como o gênero 
(Deshpande, 1997; Elm et al., 2001; Luthar et al., 1997; McDaniel et al., 2001 apud Almeida, 2007), a idade (Ruegger, King, 1992; Vitell et al., 1991 apud Almeida, 2007), o grau de instrução (Deshpande, 1997; Elm et al., 2001 apud Almeida, 2007), as orientações filosóficas (Cherry \& Frederich, 2000; Deconinck \& Lewis, 1997; Singhapakdi et al., 1999 apud Almeida, 2007) ou os valores morais (Agle et al., 1999; Carlson et al., 2002; Glover et al., 1997; Ray \& Pauli, 2002 apud Almeida, 2007). Sendo assim, pode-se afirmar que diversos fatores influenciam a ética individual e o comportamento particular diante da sociedade e nas comunidades.

Autores afirmam que o ambiente pode interferir no comportamento individual, influenciado pela opinião pública acerca da decisão tomada ou pelo nível hierárquico (posição ocupada pelo indivíduo), definindo assim, o caráter situacional do comportamento ético (Almeida, 2007).

A ética individual é influenciada por fatores socioculturais. Hofstede (1980 apud Almeida, 2007) argumenta que cada pessoa possui uma bagagem mental constituída por componentes da cultura nacional a qual está inserido, primeiramente transmitido pela família, depois escola, e depois pelo local de trabalho, o que permite manter a ordem social e tornar os comportamentos individuais previsíveis.

Whitaker (Crasp, 2008, s.p.) afirma que "Pessoa Ética é a que aplica a inteligência na procura da verdade e a vontade na busca do bem com liberdade em todas as circunstâncias”. Tal definição abarca o uso de faculdades mentais e ação próprias, buscando sempre a verdade e o bem (filosofia), pressupondo a liberdade de agir dos sujeitos.

André (2006, s.p. apud Crasp, 2008, s.p.) aplica o conceito mais analítico e sistêmico, onde afirma que a "Ética é um modelo analítico que o ser humano aplica de forma continua e consistente em todos nossos processos decisórios".

A ética individual é um conceito inacabado uma vez que não existe isolamento desse conceito em relação a sociedade na qual o indivíduo está inserido, pois aquela é influenciada pelas diversas comunidades da sociedade; escola, igreja, família, profissão, universo, etc.; e o comportamento ético implica em aprender conceitos morais e as expectativas de comportamento social, internalizar para aplicar consistentemente de forma individual (Crasp, 2008).

$\mathrm{Na}$ sociedade, as relações se alternam e se reproduzem de diversas formas (autoritárias ou liberais, possíveis ou impossíveis, aprovadas ou não), acontecendo imersas numa cultura ambivalente que fomenta conflitos e destrói certezas. Nessa perspectiva, o agir individual exige definições constantes, o que faz da ética individual extremamente importante no que concerne seu conceito de juízos universalmente válidos de busca por justiça, pelo bem individual e comum e por verdade (Agosto, 2008).

\section{Considerações Finais}

Diante os conceitos de ética como disciplina ou ciência que se ocupa dos atos morais e dos hábitos na significância de virtudes e vícios assim como dos aspectos que delimitam a ética individual, é afirmativo que essa possui papel importante nas relações sociais, como atitudes que buscam a justiças, o bem e a verdade.

Independente do século a ética é atemporal, marcando assim as relações e o agir humano.

\section{Referências}

Agosto, M. T. Abs da Cruz. (2008) Ética e relações sociais um enfoque filosófico. In JACQUES, MGC., et al. org. Relações sociais e ética. Centro Edelstein de Pesquisas Sociais, 18- 25. http://books.scielo.org

Boff, L. (2016) Causas da escandalosa falta de ética no Brasil. Jornal a Gazeta. Espírito Santo. http://www.ijsn.es.gov.br/ConteudoDigital/20160920_aj04406_etica.pdf.

Brito, J. M. R. "Os valores e a antropologia: para uma leitura fenomenológica" www.eleutheria.ufm.edu/ArticulosPDF/100621_fondo_os.

Cabanas (1998) Q. "Pedagogía axiológica: la educación ante los valores". Dykinson,

Cabral, R. (2000) "Temas de ética". Faculdade de Filosofia. Universidade Católica de Braga 
CRASP, Conselho regional de Administração de São Paulo. Grupo de excelência em Ética e sustentabilidade. (2008) Ética individual versus Ética Corporativa. CRASP., São Paulo. Disponível em:< https://crasp.gov.br/wp/wp-content/uploads/26_03_2008_etica_Individual_X_etica_Corporativa.pdf.>

Figueiredo, A. M. Ética: origens e distinção da moral. Saúde, Ética e Justiça. 13(1), 1-9.

Foucault T, M. (1998) "As palavras e as coisas". Edições 70

Frondizi, R. "Valor, estructura y situación". Dianóia, 18(18), 78-112, 1972.

Gil, A. C. Métodos e técnicas da pesquisa social. (6a ed.), Atlas

Gonçalo, E. "Os valores como fundamento ético do agir humano". Contexto, 3(3), 111-124.

Gontijo, Eduardo Dias. Os termos 'Ética'e 'Moral'. Revista Mental, 4(7).

http://pepsic.bvsalud.org/scielo.php?script=sci_arttext\&pid=S167944272006000200008>.

Hessen, J. (2001) "Filosofia dos valores". Almedina.

Jesinghaus, C. "Estudios acerca de una axiologia formal y fenomenológica". Disponível em: ffyl.uncu.edu.ar/IMG/pdf/12_vol_01_jesinghaus.pdf.

Lavelle, L. "Traité des valeurs". Théorie générale de la valeur. Tome I. PUF

Lustoza, H. K. (2013). A crise ética na sociedade brasileira. Revista jurídica Unicuritiba. 1(30), 271-283. http://revista.unicuritiba.edu.br/index.php/RevJur/article/view/563/435>.

Morente, M. Fundamentos de filosofia: ontologia dos valores (1987) http://www.consciencia.org/fundamentosfilosofiamorente22.shtml

Ortega y Gasset, J. "Obras completas". Alianza.

Pontarolo, R. "Atividade axiológica na educação". Universidade Estadual de Ponta Grossa.

Ribeiro, F. J. R. de. (2007) Ética e desempenho social das organizações: um modelo teórico de análise dos fatores culturais e contextuais. Revista de administração contemporânea, vol. 11 (3), Curitiba. Disponível em: $<$ https://www.scielo.br/j/rac/a/CsKRY4pM5sfSD59wbWDfnCB/?lang=pt $>$.

Schneeewind, J. "Dictionnaire d'éthique et de philosophie morale" (pp. 651-657). PUF

Silva, C. "Valores e valoração: posições éticas num itinerário educativo". Universidade do Porto

Singer, P. "Sobre a ética: ética prática" (pp. 9-23).

Tugendhat, E. "Lições sobre ética". Vozes.

Valadier, P. "Você disse: valores? A anarquia dos valores: será o relativismo fatal?" (pp. 15-24). Instituto Piaget

UNESCO (2021), Ética no Brasil. UNESCO - Construir a paz nas mentes dos homens e das mulheres. 